\title{
Cytotoxicity and Genotoxicity in Human Embryonic Kidney Cells Exposed to Surface Modify Chitosan Nanoparticles Loaded with Curcumin
}

\author{
Yu Zheng, ${ }^{1,2}$ Yan Chen, ${ }^{2}$ Ling-Wei Jin, ${ }^{2}$ Han-Yang Ye, ${ }^{2}$ and Gang Liu ${ }^{1,3}$
}

Received 24 August 2015; accepted 13 December 2015; published online 30 December 2015

\begin{abstract}
The rapid progress in the development and scientific investments of modified nanoparticles are due to their owed activity to various diseased conditions for which they are prepared. But the toxicity which they cause cannot be overlooked. The present study demonstrates the development of phosphatidylserine (PS)-coated chitosan (CS) nanoparticles (NPs) loaded with curcumin (CU), which was then investigated against human embryonic kidney cells (HEK 293) for its cytotoxic and genotoxic effect in rats. The CU-loaded CNPs (CNPs-CU) have been prepared by ionic gelation method, later which were grafted with PS. CNPs-CU and PS-CNPs-CU have been evaluated for their size, poly dispersity index, amount of drug entrapped, and in vitro CU release. CNPs-CU has an average size $167.6 \pm 3.53 \mathrm{~nm}$ and polydispersity index (PDI) $0.115 \pm 0.014$, whereas PS-CNPs-CU shows average size $220 \pm 3.67 \mathrm{~nm}$ and PDI $0.148 \pm 0.019$. Surface morphology of prepared NPs was confirmed by high-resolution transmission electron microscopy (HR-TEM). There was no major difference in cell viability between PS-CNPs-CU and CNPs-CU when they were exposed to HEK 293 cells at all equivalent concentrations. A series of genotoxic studies were conducted, which revealed the non-genotoxicity potential of the developed complexes. These results demonstrated that PS-CNPs-CU may be useful as potential delivery system.
\end{abstract}

KEY WORDS: chitosan nanoparticles; cytotoxicity; genotoxicity; HEK 293 cells; phosphatidylserine.

\section{INTRODUCTION}

The last few decades have witnessed a great revolution in nano-science in every way and have become an important part of our day today life; in which drug delivery, diagnostics and cosmetics are the major part of it (1). The nano therapeutics or nanoparticles (NPs) are the main focus of many research groups as it offers several benefits over conventional dosage forms such as improved bioavailability, targeted delivery. These NPs are generally consisted of biodegradable polymers or lipids which are biocompatible and are non toxic (2). But the possible toxic effect can never be denied as due to their large surface area and smaller size equivalent to the cellular components, and proteins can lead to adverse tissue reaction and causing toxicity $(3,4)$. Chitosan (CS), a polymer derived from the deacetylation (60-100\%) of chitin, is widely used as a drug delivery carrier, due to its exceptional biodegradability and biocompatibility (5). Being cationic in nature, CS offers multiple advantages for ionic interactions which can lead to development of biocompatible CNPs with a simple ionic gela-

\footnotetext{
${ }^{1}$ Department of Nephrology, The Second Hospital of Shandong University, 247 Beiyuan Street, Jinan, Shandong 250033, People's Republic of China.

${ }^{2}$ Department of Nephrology, The Second Affiliated Hospital of Wenzhou Medical University, 109 Xueyuan West Road, Wenzhou, Zhejiang 325027, People's Republic of China.

${ }^{3}$ To whom correspondence should be addressed. (e-mail: liugang3000@hotmail.com)
}

tion method (6). Cationic property of CS has also been known to produce selective adsorption and neutralizing effects on the tumor cell surface without causing any significant toxicity (7).

Curcumin (CU), highly pleiotropic molecule, secluded from Curcuma longa (turmeric) rhizome, has been proved to possess a wide spectrum of pharmacological actions (8). It has demonstrated anti-carcinogenic potential, either alone or in combination with other agents, against colorectal cancer, prostate cancer, multiple myeloma, breast cancer, oral cancer, and pancreatic cancer with a low intrinsic toxicity and also having positive effect on patients with renal conditions (9). In spite of these merits, CU suffers from its poor aqueous solubility, which in turn results in low bioavailability. CU complexed with phospholipids and its liposomes has also been evaluated to improve its oral bioavailability (10).

Phosphatidylserine (PS) is a glycerol-derived phospholipid, which plays a key role in cell cycle signaling. PS has been used as targeting legend due to its ability to be recognized by the receptors including CD68, CD14, annexins, b2 glycoprotein I (11), GAS6, and scavenger receptors (12). These receptors can play a vital role in recognition of PS-coated nanoparticles and can effectively target tumor cells of the kidney.

We have produced PS-coated CNPs loaded with CU (PSCNPs-CU) and evaluated its cytotoxicity against human embryonic kidney cells and which has been compared with pure $\mathrm{CU}$, the CNPs-CU. The further investigation for its genotoxicity was carried out in order to prove the safety of prepared PS-CNPs-CU. 


\section{MATERIALS AND METHOD}

\section{Materials}

Curcumin (CU), chitosan (CS) (70\% deacetylated), sodium azide-fluorescein isothiocyanate (FITC), fetal bovine serum (FBS), TPP, and Tween 80 were purchased from Sigma Aldrich (St. Louis, USA). All other reagents were of analytical grade. Purified water obtained from three-stage Millipore Milli-Q plus 185 purification system (Bedford, MA, USA) was used in our experiments.

\section{Preparation of CNPs-CU}

CNPs-CU was prepared by the procedure based upon ionic gelation method between CS and TPP using the method reported earlier. Briefly, the CS was dissolved in $2 \%$ acetic acid solution $(50 \mathrm{~mL})$ containing $1 \%$ of Tween- 80 for $12 \mathrm{~h}$. CU $(5 \mathrm{mg})$ solution was added drop-wise into the CS solutions on a magnetic stirrer, after which $2 \%(w / v)$ TPP solution prepared in Milli-Q water was added, and stirring was continued for $2 \mathrm{~h}$ thereby leading to formation of CNPs-CU at ambient temperature $\left(25^{\circ} \mathrm{C}\right)$. The prepared NPs were separated by centrifugation, washed three times with $10 \%$ aqueous methanol, and lyophilized. Blank CNPs have also been prepared by the method described above without adding CU.

\section{Coating of CNPs-CU and CNPs with PS}

PS was coated on CNPs-CU with the method reported earlier with slight modification. A thin layer of PS was obtained by dissolving it in chloroform:methanol (18:2) and evaporated in rotavapor at $50^{\circ} \mathrm{C}$; this layer was hydrated for $20 \mathrm{~min}$ using aqueous medium of CNPs-CU. Further, it was processed and ultra-centrifuged (Thermo Scientific Sorvall WX Ultra Centrifuge Series) at $40,000 \times \mathrm{g}$ for $30 \mathrm{~min}$ to obtain PSCNPs-CU. The blank CNPs were also coated with PS by the same described method, to form PS-CNPs.

\section{Characterization}

Average Particle Diameter, Zeta Potential, and \% Entrapment Efficiency

The average particle size, size distribution (polydispersity index [PDI]), and zeta potential of CNPs-CU, PS-CNPs-CU, blank CNPs, and PS-CNPs were determined by zetasizer 2000 (Malvern Instruments), and the zeta potential was determined by laser Doppler anemometry using a Malvern Zetasizer. All the NPs were diluted with TDW to an appropriate concentration. The measurements were carried out in the fully automatic mode.

$\%$ entrapment efficiency (\% EE) is a function of total amount of CU loaded in the CNPs-CU and PS-CNPs-CU. For the determination of \% EE CNPs-CU, PS-CNPs-CU was suspended separately in $10 \mathrm{~mL}$ of PBS centrifuged 13,000 rpm for $40 \mathrm{~min}$. The supernatant was collected as free drug and pellet as entrapped CU. The pellet is reconstituted using $5 \mathrm{ml}$ of mobile phase and analyzed by HPLC for CU content (13). HPLC estimation was conducted using mobile phase of acetonitrile:water:glacial acetic acid (650:340:10) $v / v$ on RPC18 column at $425 \mathrm{~nm}$ with a flow rate of $1.0 \mathrm{~mL} \mathrm{~min}^{-1}$.

The total amount of CU was determined as follows:

$\% \mathrm{E} . \mathrm{E}=\left[\left(W_{\mathrm{t}}-W_{\mathrm{f}}\right) / W_{\mathrm{t}}\right] \times 100$

Where, $W \mathrm{t}=$ weight of total drug and $W_{\mathrm{f}}=$ weight of unentrapped drug

Drug loading was also determined by as follows:

$\%$ drug loading $=($ amount of encapsulated CU/amount of NPs $) \times 100$

\section{High-Resolution Transmission Electron Microscopy}

The morphology of PS-CNPs-CU was observed using high-resolution transmission electron microscopy (HR-TEM) (TecnaiTM G2 F20, Eindhoven, The Netherlands) studies. A droplet of $2 \%(w / v)$ phospho-tungstic acid was added for staining. Images were obtained at a $200-\mathrm{kV}$ acceleration voltage.

\section{In vitro Release}

Briefly, plain CU, CNPs-CU, and PS-CNPs-CU (equivalent of $10 \mathrm{mg} \mathrm{CU}$ ) release was carried out using dialysis membrane (cut off mol. wt. 12 KD). CNPs-CU and PSCNPs-CU filled separately in a dialysis bag containing $1 \% \mathrm{v} /$ $v$ of Tween 80 in phosphate buffer saline and suspended in dissolution apparatus USP type II containing $500 \mathrm{ml}$ of PBS with $1 \%$ of Tween 80 , thermo-stated at $37^{\circ} \mathrm{C}$ at $100 \mathrm{rpm}$. At predetermined time intervals $(30 \mathrm{~min}, 1,2$, 4, 6, 8, 12, 18, and $24 \mathrm{~h}$ ), 1-mL sample, from the external release medium, was withdrawn and replenished with the same volume to maintain strict sink conditions throughout the experiment. The amount of released CU was estimated using HPLC.

\section{Cytotoxicity Studies}

The in vitro cellular cytotoxicity of the prepared NPs was analyzed and compared with plain CU. The assessment was carried out by the MTT assay (calorimetric assay) on human embryonic kidney cell lines (HEK 293). The principle involved in the procedure is the capability of reducing MTT into colored formazan by the viable cells, and the amount of formazan produced was a marker for cell viability. HEK cell lines were cultured in DMEM supplemented with $10 \%$ fetal calf serum and $1 \%$ antimycotica-antibiotic mixture culture plates at $37^{\circ} \mathrm{C}$ and $5 \% \mathrm{CO}_{2}$-humidified incubator. Cells seeded at a density of $1 \times 10^{5}$ cells/well in 96-well plate for $24 \mathrm{~h}$; then, cells were washed and incubated in fresh medium. NPs (CNPs and PS-CNPs, PS-CNPs-CU and CNPs-CU, with plain $\mathrm{CU})$ were added at equivalent concentration of $\mathrm{CU}(1,5$, and $10 \mu \mathrm{g} / \mathrm{mL}$ ) to triplicate wells and kept for $24 \mathrm{~h}$, after which cells were washed three times with PBS. After washing, $20 \mu \mathrm{L}$ of MTT solution (5-mg/mL stock solution) was added to each well, and cells were then incubated for additional $4 \mathrm{~h}$. The unreacted MTT dye and medium were aspirated off, and $100 \mu \mathrm{L}$ of DMSO was added to each well to ensure solubilization of formazan crystals. The contents of the plates were mixed for $15 \mathrm{~min}$ to achieve complete solubilization of the formazan crystals, and the measurement of optical density was carried 
out at $570 \mathrm{~nm}$ with a micro plate spectrophotometer (MRX Micro plate Reader, Dynatech Laboratories Inc., Chantilly, VA, US) at $570 \mathrm{~nm}$.

\section{In vivo Studies}

For animal experiments, 6-8-week-old healthy Balb/c mice with the average body weight (BW) of $25 \pm 5 \mathrm{~g}$ were employed for the micronucleus (MN) assay as well as chromosome aberration (CA) assay. The animals were kept at the temperature of $23 \pm 1{ }^{\circ} \mathrm{C}$ with humidity of $55 \pm 5 \%$, in a 14 -h light/10-h dark cycle. Animals were on soy-free and filtered drinking water.

\section{Genotoxic Studies}

The genotoxic potential of CNPs-CU and PS-CNPs-CU was evaluated by short-term assays measuring aneugenicity and clastogenicity. Experiments were carried out according to the reported procedures (14). The genotoxicity study was carried out by dividing the animals in five test groups: positive control; cyclophosphamide, $40 \mathrm{mg} / \mathrm{kg}$ BW CNPs-CU (having $100 \mathrm{mg} / \mathrm{kg}$ of CU equivalent dose); PS-CNPs-CU (having $100 \mathrm{mg} / \mathrm{kg}$ of $\mathrm{Cu}$ equivalent dose); vehicle control; and distilled water.

\section{Micronucleus Assay}

Healthy Balb/c mice, $n=4$, were administered with the daily assigned dose for consecutive 2 days suspended in $0.25 \mathrm{~mL}$ of the vehicle. After which, the mice were sacrificed (cervical dislocation) to isolate the bone marrow cells from both the femurs, and the bone marrow was collected in $5 \mathrm{~mL}$ of fetal bovine serum (FBS) with the help of a $22 \mathrm{G}$ needle and mixed homogeneously to facilitate the cell collection. This cell suspension was centrifuged at $3000 \mathrm{rpm}$ for $5 \mathrm{~min}$, and the pellet was collected, which was then suspended and mixed in the residue fetal bovine serum (FBS) (about $100 \mu \mathrm{L}$ ). The cells were spread over a clear glass slide to obtain a single layer of smear which was fixed with methanol for $5 \mathrm{~min}$ and was stained with $0.25 \%$ solution of May-Grunwald (Himedia) stain in methanol for $2 \mathrm{~min}$ and in Giemsa (Sigma) for $10 \mathrm{~min}$ and finally, mounted with cover glass and DPX. The prepared slides were monitored at $100 \times$ magnification of microscope (Leica, Germany). At least 1000 polychromatic erythrocytes (PCEs) were observed for the assessment of micronuclei for assessing the genotoxicity along with normochromatic erythrocytes with or without micronucleus.

\section{Chromosome Aberration Assay}

Healthy Balb/c mice, $n=4$, were administered with the daily assigned dose for consecutive 2 days suspended in $0.5 \mathrm{~mL}$ of the vehicle. At the end of the treatment, the mice were administered intraperitoneally with $4 \mathrm{mg} / \mathrm{kg}$ BW of colchicine and were sacrificed by cervical dislocation after $2 \mathrm{~h}$. The bone marrow cells from both the femurs were collected in $5 \mathrm{ml}$ of $1 \%$ sodium citrate and mixed homogeneously and incubated at $37^{\circ} \mathrm{C}$ for $10 \mathrm{~min}$. The resulting pellet is treated with a $3 \mathrm{ml}$ of hypotonic solution $(0.075 \mathrm{M} \mathrm{KCl})$, mixed gently, and incubated at $37^{\circ} \mathrm{C}$ for $20 \mathrm{~min}$. This cell suspension was centrifuged at $3000 \mathrm{rpm}$ for $5 \mathrm{~min}$, and the pellet was collected. The cell pellet was mixed with $3-\mathrm{mL}$ cold Carnoy's fixative (glacial acetic acid/methanol, 1:3v/v). The process was repeated for three times, and finally, 200- $\mu$ L fresh Carnoy's fixative was added to the suspension. And the cells were spread over a chilled clear glass, dried on a hot plate at $45^{\circ} \mathrm{C}$ for $5 \mathrm{~min}$, and stained for 5 min with a freshly prepared $10 \%(v / v)$ Giemsa's (Sigma) solution in Sorenson buffer which mounted with cover glass and DPX. The prepared slides were monitored at
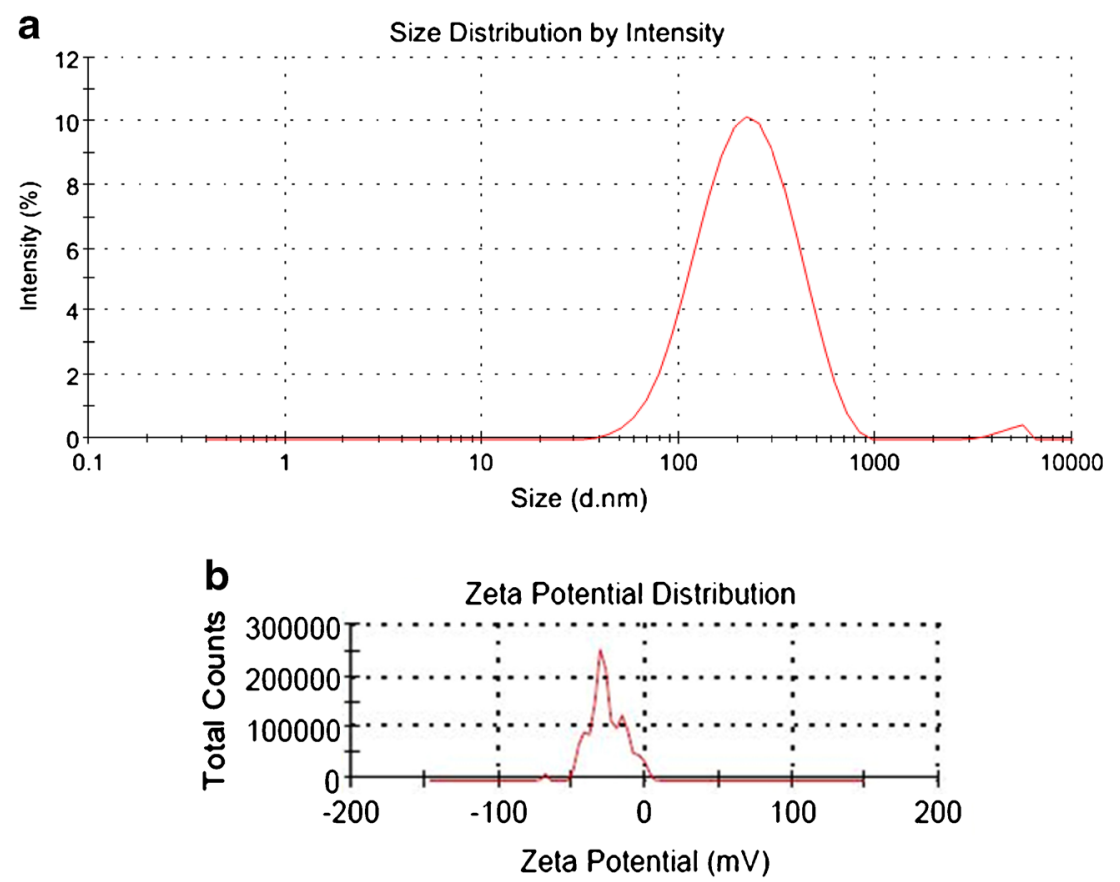

Fig. 1. a Size distribution of PS-CNPs-CU and $\mathbf{b}$ zeta potential distribution of PS-CNPs-CU 


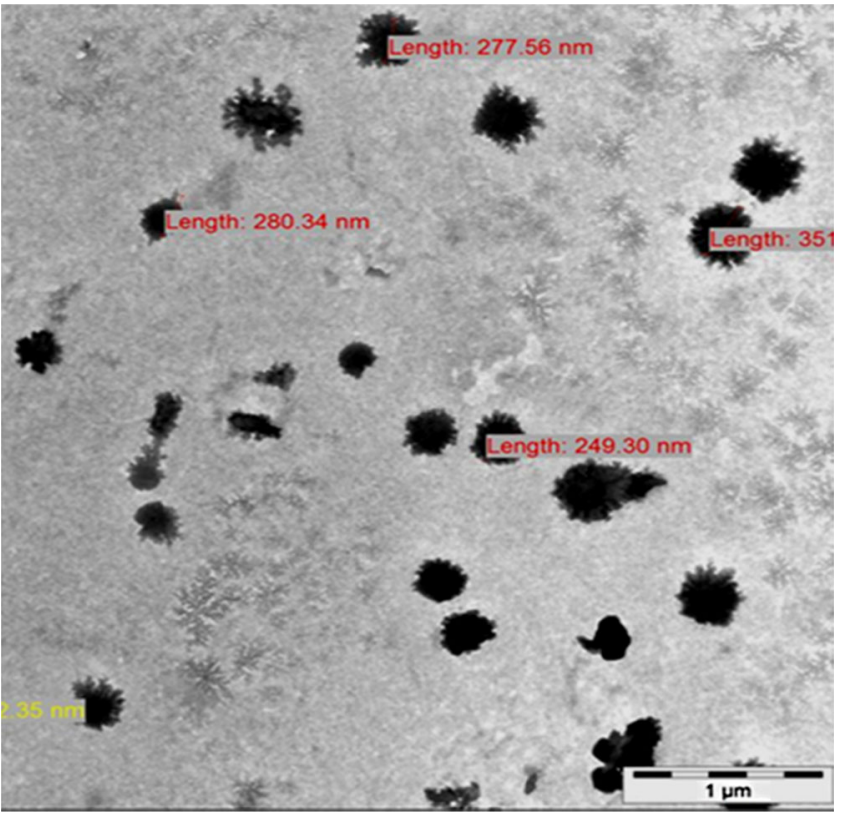

Fig. 2. HR-TEM images of PS-CNPs-CU

$100 \times$ magnification of microscope (Leica, Germany). One hundred well-spread metaphase cells were observed for CA determination as a marker of genotoxicity.

\section{Statistical Analysis}

Statistical analysis was carried out using one-way analysis of variance (ANOVA). $P<0.001$ was considered to be statistically significant.

\section{RESULTS}

\section{Preparation of CNPs-CU and Blank CNPs}

The ionic gelation method allowed us to prepare uniform CNPs-CU and blank CNPs successfully with low polydispersity index (PDI) $(<0.2)$. The CNPs have been prepared by excluding the step of addition of CU. The measured particle size and size distributions of the CNPs and CNPs-CU measured by dynamic light scattering (DLS) were found to be $99.6 \pm 2.15 \mathrm{~nm}$ and 167.6 $\pm 3.53 \mathrm{~nm}$, respectively with narrow size distributions.

\section{Preparation of PS-CNPs-CU and PS-CNPs and Their Characterization}

The CNPs-CU and CNPs were finally coated with PS by hydrating the phospholipid film with CNPs-CU and CNPs dispersion. The mean diameter of the PS-CNPs-CU was
$220.5 \pm 3.67$ with PDI of 0.148 , which was slightly higher than that of CNPs-CU, which might be due to the coating layer of PS on CNPs-CU. The major transform was observed in the zeta potential of the NPs. The CNPs-CU showed the positive zeta potential $21.9 \pm 1.31 \mathrm{mV}$ whereas PS-CNPs-CU has negative zeta potential $-25.4 \pm 2.13 \mathrm{mV}$ (Fig. 1). This might be due to the complete mask of the CNPs-CU by PS coating. The presence of PS on the surface of CNPs-CU was verified by using TEM. Figure 2 shows the morphological characteristics of the PS coating on CNPs-CU by TEM. Lipidic layering was observed as a continuous layer over CNPs; \% EE in PS-CNPsCU was found to be $50.4 \pm 3.7 \%$, which was less when compared to that in CNPs-CU $(59.4 \pm 3.1 \%)$ which may be qualified to the loss of $\mathrm{CU}$ during the coating process of CNPs-CU with PS as shown in Table I.

The \% loading was found to be $5.04 \pm 1.23$ for PS-CNPs-CU.

\section{In vitro Release}

The in vitro release profile of $\mathrm{CU}$ from plain $\mathrm{CU}$, PSCNPs-CU, and CNPs-CU was studied by using pretreated dialysis bag (Sigma; cut off MW-12 KD) at pH 7.4 using Tween 80 to facilitate the release of $\mathrm{CU}$ in the medium. The in vitro release of PS-CNPs-CU and CNPs-CU displayed fairly controlled release profile. The release profile of $\mathrm{CU}$ was monitored using HPLC method as described previously. The amount of $\mathrm{CU}$ released at $\mathrm{pH} 7.4$ was 31.82 and $22.64 \%$ for CU-CNPs and PS-CNPs after $2 \mathrm{~h}$ at $37^{\circ} \mathrm{C}$. The initial retard in the release of PS-CNPs-CU might be due to the slow rupture of PS coating and then the release of $\mathrm{CU}$ from it. $\mathrm{CU}$ released in the next $12 \mathrm{~h}$ was 81.82 and $73.77 \%$ from CNPs-CU and PSCNPs-CU, respectively (Fig. 3). After $24 \mathrm{~h}$, the release was found to be 94.17 and $83.94 \%$ for CNPs-CU and PS-CNPs$\mathrm{CU}$, respectively. This data indicates that formulation retard $\mathrm{CU}$ release in the medium.

\section{Cytotoxicity Studies}

The cytotoxicity of formulations was determined in HEK 293 cell lines by MTT assay. The cell cytotoxicity remained $<10 \%$ for both CNPs and PS-CNPs against HEK 293 cell lines at all equivalent concentrations indicating safety of excipients used. The cell cytotoxicity at higher equivalent concentrations $(1,5$, and $10 \mu \mathrm{g} / \mathrm{mL})$ of PS-CNPs-CU was more than that of CNPs-CU. This might be due to the fact that the uptake of PSCNPs-CU was significantly high in comparison to CNPs-CU in macrophages but it is possible that the slower release of $\mathrm{CU}$ from PS-CNPs-CU and CNPs-CU in comparison to plain $\mathrm{CU}$ reduces the cytotoxicity of PS-CNPs-CU and CNPs-CU. At lower concentration $(1 \mu \mathrm{g} / \mathrm{ml})$, PS-CNPs-CU and CNPs-CU showed less than $5 \%$ of cell cytotoxicity. The data has been represented in Fig. 4.

Table I. Particle Size, PDI, Zeta Potential, and \% EE

\begin{tabular}{|c|c|c|c|c|c|}
\hline Formulation & Size $(\mathrm{nm})$ & Poly dispersity index (PDI) & Zeta-potential (mV) & $\%$ entrapment efficiency & $\%$ loading \\
\hline CNPs & $99.8 \pm 2.15$ & $0.072 \pm 0.02$ & $19.9 \pm 1.27$ & - & \\
\hline CNPs-CU & $167.6 \pm 3.53$ & $0.115 \pm 0.014$ & $21.9 \pm 1.31$ & $59.4 \pm 3.1$ & $5.94 \pm 1.8$ \\
\hline PS-CNPs & $176.7 \pm 2.21$ & $0.124 \pm 0.016$ & $-19.9 \pm 1.33$ & - & \\
\hline PS-CNPs-CU & $220.5 \pm 3.67$ & $0.148 \pm 0.019$ & $-25.4 \pm 2.13$ & $50.4 \pm 3.7$ & $5.04 \pm 1.23$ \\
\hline
\end{tabular}




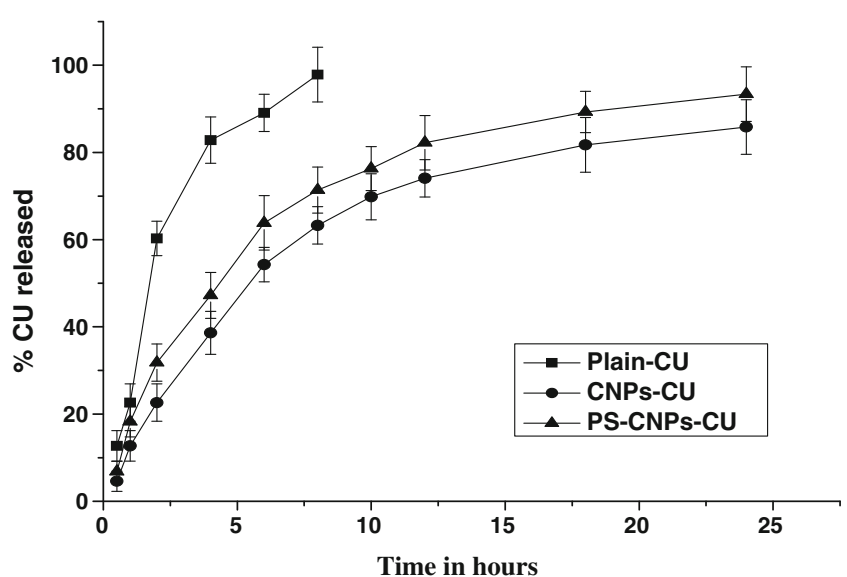

Fig. 3. In vitro $\mathrm{CU}$ release from CNPs-CU and PS-CNPs-CU in PBS containing $1 \%$ of Tween 80

\section{Genotoxicity Testing}

\section{Micronucleus Assay}

The administration of CNPs-CU and PS-CNPs-CU did not result in any significant increase in the rate of micronucleated cells, in the animals, when compared with the cyclophosphamide-treated mice. However, a significant increase in $(p<0.001)$ of micronucleated cells was observable in the animals treated with cyclophosphamide. CNPs-CU and PS-CNPs-CU were comparable with the control, which were non-clastogenic. The results have been depicted in Fig. 5.

\section{Chromosome Aberration Assay}

The administration of CNPs-CU and PS-CNPs-CU did not induce aberrations and was comparable to the control. Cyclophosphamide-treated mice, however, produced a significant number $(p<0.001)$ of aberrations. The results clearly indicates that CNPs-CU and PS-CNPs-CU are non- clastogenic in nature. The results have been depicted in Fig. 6.

\section{DISCUSSION}

The analysis of NPs vulnerability is becoming a major concern for toxicologists involved in NP toxicity as the wide spectrum of NPs variability in their compositions, sizes and shape can be hazardous. The consideration of NPs-associated

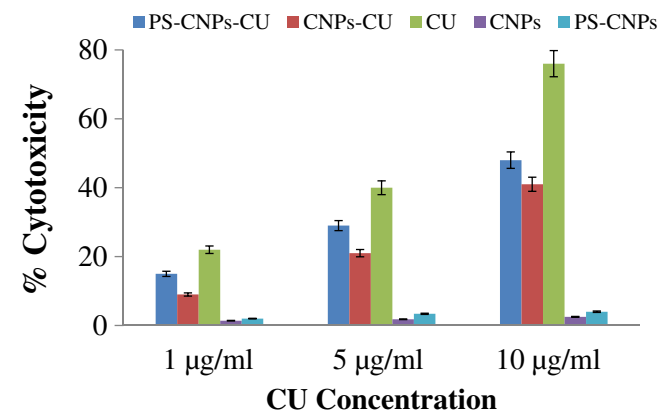

Fig. 4. \% cell cytotoxicity of HEK 293 cells exposed to concentrations 1,5 , and $10 \mu \mathrm{M}$ of CU, CNPs-CU, PS-CNPs-CU, CNPs, and PS-CNPs. The cell cytotoxicity was measured via the MTT assay

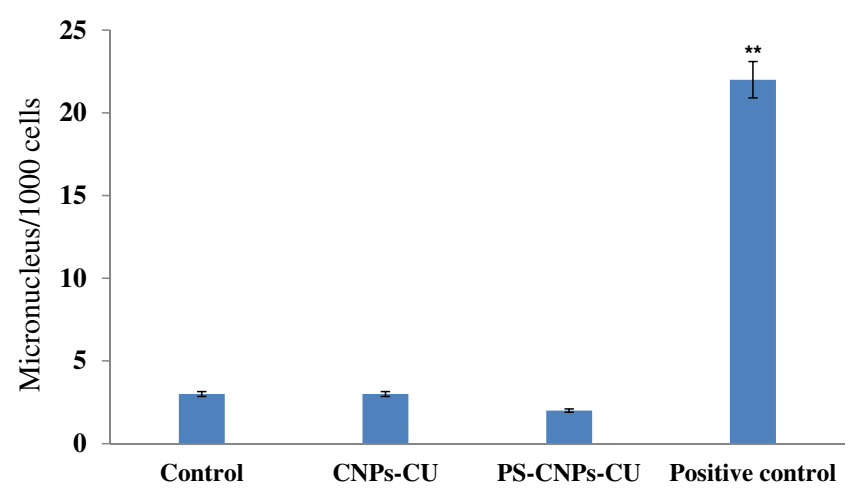

Fig. 5. Micronucleus assay: in bone marrow cells of mice. ${ }^{* *} P<0.0001$

hazards is prerequisite for risk assessment and safety (15). We have developed a drug delivery system, CNPs, as CS has various positive factors such as its biocompatibility, degradability, and nontoxic, and also, the absorption drug encapsulated into CNPs can be improved and can also effectively protect them effectively from enzyme degradation in vivo. The NPs of CS molecules were prepared using TPP via electrostatic interaction, the formation of which was indicated by its opalescence appearance. Furthermore, by ionic gelation method, the development of CNPs-CU has been carefully controlled to achieve the preferred property like uniformity in NPs with low polydispersity (5). CNPs can also be modified achieving sustained or controlled release and targeting (16). We have loaded CU, a plant drug in CNPs as the active antitumor components as our model drug. CU has a strong anti-proliferative activity, and its low toxicity has attracted particular interest and was preferred as potential agent for adjunct chemotherapy. This golden spice turmeric (Curcuma longa) has been reported to effect number of cell signaling pathways (17). CU has been reported as a nutraceutical with having numerous positive effects in patients having various pro-inflammatory diseases including cancer, arthritis, renal conditions, etc. with additional effect on alcohol intoxication and hepatic conditions (18). CU suffers with poor bioavailability which makes a hurdle in the utility of it as a therapeutic (19).

This CNPs-CU was further decorated with PS with the simple method reported earlier. PS has been coated on NPs as PS can be recognized by the receptors, including scavenger

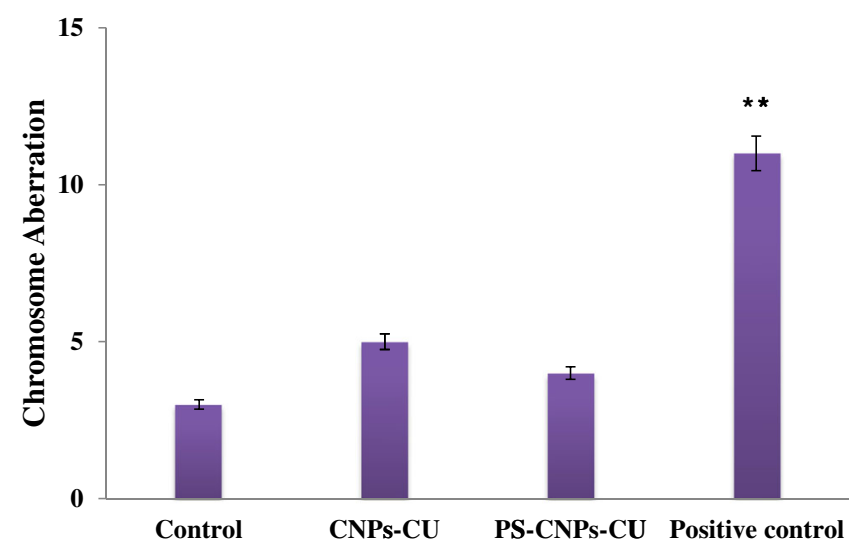

Fig. 6. Chromosome aberration assay: in bone marrow cells of mice. $* * P<0.0001$ 
(class B, CD36/SR-BI; and class A, MARCO), CD68 (an oxLDL receptor), CD14, annexins, $\beta 2$ glycoprotein I, and GAS6, and the NPs can be target or uptaken easily (20).

PS-CNPs-CU has shown a synergistic effect on concentration-dependent study in reduction of cell viability. The cell cytotoxicity of PS-CNPs-CU was found to be higher than that of CNPs-CU at all concentrations (1, 5, and $10 \mu \mathrm{g} /$ $\mathrm{mL})$. The $\mathrm{CU}$ alone shows higher cell viability as compared to other CU-loaded NPs which may be assigned to their size influenced improved cellular internalization. In addition, increased permeability of the NPs may also be attributed due to the inhibition of P-glycoprotein effluence pump.

Genotoxicity studies were carried out to calculate the potential effects PS-CNPs-CU and CNPs-CU on DNA/chromosomes, which are critical issues and can be carcinogenic by initiating oncogene activation, or they may suppress the tumor suppressor genes. These tests are also important to identify any probability of mutagenicity in the germ cells caused by the drug $(21,22)$. Cyclophosphamide has been used as a positive control in our experiments to visualize the induced aberrations accurately; the mice were administered with colchicine intraperitoneally before sacrificing which has the ability to arrest the mitotic cells in the cell cycle (22).

\section{CONCLUSION}

The CNPs-CU was prepared using ionic gelation method with low polydispersity index (PDI) $(<0.2)$ with particle size of 100 to $200 \mathrm{~nm}$. PS was coated to CNPs-CU and CNPs by hydrating the phospholipid film which resulted in the formation of PS-CNPs-CU of size $220.5 \pm 3.67$ with \% EE of 50.4 $\pm 3.7 \%$. The cytotoxicity results in HEK 293 cell lines demonstrate the efficacy of PS-CNPs-CU over CNPs-CU. The PSCNPs-CU and CNPs-CU which were subjected for genotoxic studies to evaluate the potential effects on DNA/ chromosomes demonstrated no evidence of chromosome or DNA damage revealing the safety of them.

\section{ACKNOWLEDGMENTS}

The authors were grateful for the support and facilities provided by Department of Nephrology, The Second Hospital of Shandong University, P.R. China.

\section{COMPLIANCE WITH ETHICAL STANDARDS}

Conflict of Interest conflict of interest.

The authors declare that they have no

\section{REFERENCES}

1. Wang Q. Nanoparticles for applications in drug delivery.

2. Dwivedi P, Kansal S, Sharma M, Shukla R, Verma A, Shukla P, et al. Exploiting 4-sulphate N-acetyl galactosamine decorated gelatin nanoparticles for effective targeting to professional phagocytes in vitro and in vivo. J Drug Target. 2012;20(10):88396.

3. Vorup-Jensen T, Peer D. Nanotoxicity and the importance of being earnest. Adv Drug Deliv Rev. 2012;64(15):1661-2.

4. Donaldson K, Poland CA. Nanotoxicity: challenging the myth of nano-specific toxicity. Curr Opin Biotechnol. 2013;24(4):724-34.

5. Tiyaboonchai W. Chitosan nanoparticles: a promising system for drug delivery. Naresuan Univ J: Scie Technol. 2013;11(3):51-66.

6. Khatik R, Mishra R, Verma A, Dwivedi P, Kumar V, Gupta V, et al. Colon-specific delivery of curcumin by exploiting Eudragitdecorated chitosan nanoparticles in vitro and in vivo. J Nanoparticle Res. 2013;15(9):1-15.

7. Riva R, Ragelle H, des Rieux A, Duhem N, Jérôme C, Préat V. Chitosan and chitosan derivatives in drug delivery and tissue engineering. Chitosan for biomaterials II: Springer; 2011. p. 1944.

8. Gupta SC, Patchva S, Koh W, Aggarwal BB. Discovery of curcumin, a component of golden spice, and its miraculous biological activities. Clin Exp Pharmacol Physiol. 2012;39(3):283-99.

9. Gupta SC, Patchva S, Aggarwal BB. Therapeutic roles of curcumin: lessons learned from clinical trials. AAPS J. 2013;15(1):195-218.

10. Khatik R, Dwivedi P, Shukla A, Srivastava P, Rath SK, Paliwal SK, et al. Development, characterization and toxicological evaluations of phospholipids complexes of curcumin for effective drug delivery in cancer chemotherapy. Drug Deliv. 2014:1-12.

11. Fadok VA, Bratton DL, Frasch SC, Warner ML, Henson PM. The role of phosphatidylserine in recognition of apoptotic cells by phagocytes. Cell Death Differ. 1998;5(7):551-62.

12. Kansal S, Tandon R, Dwivedi P, Misra P, Verma PR, Dube A, et $a l$. Development of nanocapsules bearing doxorubicin for macrophage targeting through the phosphatidylserine ligand: a system for intervention in visceral leishmaniasis. J Antimicrob Chemother. 2012;67(11):2650-60.

13. Khatik R, Dwivedi P, Junnuthula VR, Sharma K, Chuttani K, Mishra AK, et al. Potential in vitro and in vivo colon specific anticancer activity in a HCT-116 xenograft nude mice model: targeted delivery using enteric coated folate modified nanoparticles. RSC Adv. 2015;5(21):16507-20. doi:10.1039/C4RA15114C.

14. More AB, Chilgunde SN, Kamble JC, Patil PS, Malshe VC, Vanage GR, et al. Polyethylene sebacate: genotoxicity, mutagenicity evaluation and application in periodontal drug delivery system. J Pharm Sci. 2009;98(12):4781-95.

15. Love SA, Maurer-Jones MA, Thompson JW, Lin Y-S, Haynes CL. Assessing nanoparticle toxicity. Annu Rev Anal Chem. 2012;5:181-205.

16. Chaudhury A, Das S. Recent advancement of chitosan-based nanoparticles for oral controlled delivery of insulin and other therapeutic agents. AAPS PharmSciTech. 2011;12(1):10-20.

17. Anitha A, Deepagan V, Rani VD, Menon D, Nair S, Jayakumar $\mathrm{R}$. Preparation, characterization, in vitro drug release and biological studies of curcumin loaded dextran sulphate-chitosan nanoparticles. Carbohydr Polym. 2011;84(3):1158-64.

18. Wilken R, Veena MS, Wang MB, Srivatsan ES. Curcumin: a review of anti-cancer properties and therapeutic activity in head and neck squamous cell carcinoma. Mol Cancer. 2011;10(12):1-19.

19. Zhou H, Beevers CS, Huang S. Targets of curcumin. Curr Drug Targets. 2011;12(3):332.

20. He M, Kubo H, Morimoto K, Fujino N, Suzuki T, Takahasi T, et al. Receptor for advanced glycation end products binds to phosphatidylserine and assists in the clearance of apoptotic cells. EMBO Rep. 2011;12(4):358-64.

21. Rao KS, Xu Y, Shaw E, Parton JW. Mutagenicity testing applied for regulation of developing products. Curr Sep. 2004:20:141-4.

22. Putman DL, Clarke JJ, Escobar P, Gudi R, Krsmanovic LS, Pant $\mathrm{K}$, et al. Toxicological testing handbook principles, applications, and data interpretation. In: Jacobson-Kram D, Keller KA, editors. Genetic toxicology. New York: Informa Healthcare USA, Inc; 2006. 